\title{
Predicting Incident Multimorbidity
}

Luke T. A. Mounce, $P b D^{1}$

John L. Campbell, $M D^{1}$

William E. Henley, $P b D^{1}$

Maria C. Tejerina Arreal, $P b D$, $M P H, L C P^{2}$

Ian Porter, $P b D^{1}$

Jose M. Valderas, BMBS, $P b D, M P H^{1}$

'University of Exeter Medical School,

St Luke's Campus, Exeter, Devon,

United Kingdom

${ }^{2}$ Faculty of Psychology, University of Murcia, Murcia, Spain

Conflicts of interest: authors report none.

\section{CORRESPONDING AUTHOR}

Jose M. Valderas, BMBS, PhD, MPH Health Services and Policy Research University of Exeter Medical School Smeall Building, St Luke's Campus, Magdalen Rd

Exeter, Devon, EX2 5LU, United Kingdom J.M.Valderas@exeter.ac.uk

\begin{abstract}
PURPOSE Multimorbidity is associated with adverse outcomes, yet research on the determinants of its incidence is lacking. We investigated which sociodemographic, health, and individual lifestyle (eg, physical activity, smoking behavior, body mass index) characteristics predict new cases of multimorbidity.
\end{abstract}

METHODS We used data from 4,564 participants aged 50 years and older in the English Longitudinal Study of Aging that included a 10-year follow-up period. Discrete time-to-event (complementary log-log) models were constructed for exploring the associations of baseline characteristics with outcomes between 2002-2003 and 2012-2013 separately for participants with no initial conditions $(n=1,377)$ developing multimorbidity, any increase in conditions within 10 years regardless of initial conditions, and the impact of individual conditions on incident multimorbidity.

RESULTS The risks of developing multimorbidity were positively associated with age, and they were greater for the least wealthy, for participants who were obese, and for those who reported the lowest levels of physical activity or an external locus of control (believing that life events are outside of one's control) for all groups regardless of baseline conditions (all linear trends <.05). No significant associations were observed for sex, educational attainment, or social detachment. For participants with any increase in conditions $(n=4,564)$, a history of smoking was the only additional predictor. For participants with a single baseline condition $(n=1,534)$, chronic obstructive pulmonary disease (COPD), asthma, and arrhythmia showed the strongest associations with subsequent multimorbidity.

CONCLUSIONS Our findings support the development and implementation of a strategy targeting the prevention of multimorbidity for susceptible groups. This approach should incorporate behavior change addressing lifestyle factors and target health-related locus of control.

Ann Fam Med 2018;16:322-329. https://doi.org/10.1370/afm.2271.

\section{INTRODUCTION}

$\mathrm{T}$ The rising tide of multimorbidity ( 2 or more concurrent conditions $)^{1}$ is a major challenge facing health care systems worldwide. ${ }^{2-4}$ Multimorbidity is associated with significant reductions in functional status and quality of life, ${ }^{5,6}$ increased risk of premature death, ${ }^{7}$ and substantially increased use of health service care. ${ }^{8,9}$ A number of interventions have been developed and evaluated for improving health and health care outcomes of persons with prevalent multimorbidity, although uncertainties remain about their effectiveness. ${ }^{10,11}$

An alternative strategy would be preventing the development of multimorbidity, ${ }^{12}$ which could be achieved through better implementation of multiple existing, condition-specific, preventive strategies., ${ }^{43-15}$ It may be possible, however, to develop more efficient strategies addressing common determinants of multimorbidity across a wide range of conditions. Ascertaining the key determinants of multimorbidity is an essential prerequisite for developing our knowledge of the pathogenesis of multimorbidity, for the early identification of individuals at risk, and for informing effective public health and health care-oriented strategies. ${ }^{12}$

Consistent associations have been found, mostly in cross-sectional studies ${ }^{16}$ between multimorbidity and older age, lower socioeconomic status, 
and mental health problems, and less consistently with the female sex. ${ }^{4,8,13,17-19}$ Large gaps remain in our knowledge regarding determinants of multimorbidity, however. Longitudinal investigations are needed to confirm observations from cross-sectional studies and to explore lifestyle predictors, as well as sociodemographic factors. ${ }^{16,20,21}$ A recent systematic review also highlighted the lack of studies investigating the impact of specific conditions with the development of multimorbidity. ${ }^{16,22}$

We sought to help redress these gaps in the current understanding through the present study. Our goal was to use longitudinal data to investigate which sociodemographic, health, and lifestyle characteristics (eg, physical activity, smoking behavior, body mass index $[\mathrm{BMI}])$ were predictive of incident conditions during a 10 -year period. We explored factors associated with time to subsequent multimorbidity for participants with no conditions at baseline, and with time to any increase in conditions for all participants, regardless of baseline morbidity, as well as the impact of individual conditions.

\section{METHODS}

\section{Study Design and Data Source}

The English Longitudinal Study of Aging (ELSA) cohort was selected to be representative of adults aged 50 years and older living in private households in England ${ }^{23}$ ELSA collects information from participants through face-to-face interviews every 2 years (baseline in 2002-2003), with an additional nurse visit at every 2-year wave. Detailed descriptions of the sampling and data collection methods are published elsewhere. ${ }^{23-26} \mathrm{We}$ included participants who were interviewed in all 6 consecutive waves of ELSA from 2002-2003 to 2012-2013.

\section{Multimorbidity}

At each wave, participants self-reported whether a physician had diagnosed any of the following 15 conditions included in ELSA (excluding eye conditions, which are not typically included in measures of multimorbidity): hypertension, ischemic heart disease (angina or myocardial infarction), congestive heart failure, heart arrhythmia, diabetes mellitus, stroke, chronic obstructive pulmonary disease, asthma, arthritis (any), osteoporosis, cancer (any), Parkinson's disease, 1 or more affective mental health conditions (depression, anxiety, or emotional problems), 1 or more psychotic mental health conditions (schizophrenia, psychosis, bipolar disorder, or hallucinations), and dementia (including Alzheimer's disease). For an affective mental health condition, we ascertained at each follow-up whether the condition(s) was in remission. At each wave, variables were created for the number of conditions reported by participants, whether they had multimorbidity ( 2 or more condi- tions), and whether they reported an increased number of conditions since the previous wave.

\section{Participant Characteristics}

We obtained information from 2002-2003 on participants' age (5-year groups), sex, total wealth (converted to quintiles), education level (higher, intermediate [secondary/ high school], no qualifications), BMI category (assessed at the 2004-2005 nurse visit), smoking behavior (never, past, current), physical activity (Allied Dunbar fitness survey: high, moderate, low/sedentary) ${ }_{1}{ }^{27}$ social detachment ${ }^{28}$ whether they live alone, and locus of control (the extent to which they believe life events are outside their control). Details on the derivation of covariates are provided in the Supplement Appendix, available at http://www. AnnFamMed.org/content/16/4/322/supp1/DC1/.

\section{Statistical Analysis}

We present trends in multimorbidity and individual conditions across the 10-year study and the patterns of co-occurring conditions in 2012-2013 with relative risks.

We constructed 3 discrete time-to-event complementary log-log models (equivalent to Cox proportional hazards models for continuous time) to explore the associations of baseline characteristics with acquiring incident conditions between 2002-2003 and 2012-2013 (a nonparametric specification of the baseline hazard was used). The first model included individuals with no initial conditions and used having 2 or more incident conditions (multimorbidity) as the outcome. The second included all participants, regardless of baseline morbidity, with 1 or more incident conditions as the outcome. Ordinal variables were entered as dummy variables to investigate any threshold effects in their categories and as continuous variables to test for linear trends. The final model was constructed with individual conditions in 2002-2003 as predictors, included participants with 1 initial condition only, and used 1 or more incident conditions (and therefore multimorbidity) as the outcome. This model controlled for baseline characteristics.

Longitudinal sample weighting was used to account for differential nonresponse, the details of which are provided in the ELSA technical report. ${ }^{23}$ Multiple imputation of missing data was used throughout. All analyses were conducted using Stata $\backslash$ E v15.1 (Stata Corp).

\section{RESULTS}

A total of 12,100 participants completed the baseline interview, of whom 4,564 (37.7\%) completed all 5 subsequent 2 -year waves and were included in our analyses. The characteristics of this sample are displayed in Table 1 . The prevalence of multimorbidity and individual conditions across the study period is shown 
Table 1. Participants' Characteristics at Baseline (2002-2003) and Outcomes at End of Study (2012-2013)

\begin{tabular}{|c|c|c|c|c|}
\hline Characteristic & Total Sample & $\begin{array}{l}\text { No Condition } \\
\text { at Baseline }\end{array}$ & $\begin{array}{l}1 \text { Condition } \\
\text { at Baseline }\end{array}$ & $\begin{array}{c}\geq 2 \text { Conditions } \\
\text { (Multimorbidity) } \\
\text { at Baseline }\end{array}$ \\
\hline All eligible, No. (\%) & $4,564(100.0)$ & $1,477(32.4)$ & $1,534(33.6)$ & $1,553(34.0)$ \\
\hline Multimorbidity by $2012-2013$, No. (\%) & $2,897(63.5)$ & $377(25.5)$ & $1,001(65.3)$ & NA \\
\hline$\geq 1$ Additional condition by $2012-2013$, No. (\%) & $2,845(62.3)$ & $901(61.0)$ & $1,001(65.3)$ & $943(60.7)$ \\
\hline \multicolumn{5}{|l|}{ Age-group, No. (\%) } \\
\hline $50-54$ y & $1011(22.2)$ & $462(31.3)$ & $347(22.6)$ & $202(13.0)$ \\
\hline $55-59$ y & $1093(24)$ & $392(26.5)$ & $372(24.3)$ & $329(21.2)$ \\
\hline $60-64$ y & $792(17.4)$ & $245(16.6)$ & $272(17.7)$ & $275(17.7)$ \\
\hline $65-69$ y & $762(16.7)$ & $182(12.3)$ & $266(17.3)$ & $314(20.2)$ \\
\hline $70-74$ y & $518(11.4)$ & $130(8.8)$ & $158(10.3)$ & $230(14.8)$ \\
\hline $75-79$ y & $267(5.9)$ & $48(3.3)$ & $86(5.6)$ & $133(8.6)$ \\
\hline $80-84$ y & $103(2.3)$ & $15(1.0)$ & $27(1.8)$ & $61(3.9)$ \\
\hline$\geq 85$ y & $18(0.4)$ & $3(0.2)$ & $6(0.4)$ & $9(0.6)$ \\
\hline Female, No. (\%) & $2,570(56.3)$ & $737(49.9)$ & $856(55.8)$ & $977(62.9)$ \\
\hline \multirow[t]{2}{*}{ Total wealth, median (IQR), $\mathrm{E}$} & $166,899.7$ & 190,500 & 181,000 & $134,742.6$ \\
\hline & $(82,689-303,170.1)$ & $(105,039.6-337,505)$ & $(893,45.5-315,573.5)$ & $(57,158.52-254,200)$ \\
\hline \multicolumn{5}{|l|}{ Wealth quintile, No. (\%) } \\
\hline 1 Wealthiest & $896(19.6)$ & $354(24.0)$ & $329(21.5)$ & $213(13.7)$ \\
\hline 2 & $896(19.6)$ & $290(19.6)$ & $325(21.2)$ & $281(18.1)$ \\
\hline 3 & $896(19.6)$ & $333(22.6)$ & $284(18.5)$ & $279(18.0)$ \\
\hline 4 & $898(19.7)$ & $258(17.5)$ & $298(19.4)$ & $342(22.0)$ \\
\hline 5 Least wealthy & $897(19.7)$ & $214(14.5)$ & $268(17.5)$ & $415(26.7)$ \\
\hline Missing & $81(1.8)$ & $28(1.9)$ & $30(2.0)$ & $23(1.5)$ \\
\hline \multicolumn{5}{|l|}{ Educational attainment, No. (\%) } \\
\hline Undergraduate degree or higher & $1,342(29.4)$ & $508(34.4)$ & $451(29.4)$ & $383(24.7)$ \\
\hline Intermediate & $1,801(39.5)$ & $601(40.7)$ & $616(40.2)$ & $584(37.6)$ \\
\hline No qualifications & $1,421(31.1)$ & $368(24.9)$ & $467(30.4)$ & $586(37.7)$ \\
\hline Lives alone, No. (\%) & $2,823(61.9)$ & $921(62.4)$ & $930(60.3)$ & $972(62.6)$ \\
\hline \multicolumn{5}{|l|}{ BMI category, No. (\%) } \\
\hline Underweight & $25(0.6)$ & $10(0.7)$ & $9(0.6)$ & $6(0.4)$ \\
\hline Normal weight & $1,086(23.8)$ & $428(29.0)$ & $371(24.2)$ & $287(18.5)$ \\
\hline Overweight & $1,835(40.2)$ & $626(42.4)$ & $623(40.6)$ & $586(37.7)$ \\
\hline Obese & $1,187(26.0)$ & $293(19.8)$ & $389(25.4)$ & $505(32.5)$ \\
\hline Missing & $431(9.4)$ & $120(8.1)$ & $142(9.3)$ & 169 (10.9) \\
\hline \multicolumn{5}{|l|}{ Smoking behavior, No. (\%) } \\
\hline Never smoked & $1,772(38.8)$ & $604(40.9)$ & $613(40.0)$ & $555(35.7)$ \\
\hline Smoked in past & $2,101(46.0)$ & $642(43.5)$ & $696(45.4)$ & $763(49.1)$ \\
\hline Current smoker & $691(15.1)$ & $231(15.6)$ & $225(14.7)$ & $235(15.1)$ \\
\hline \multicolumn{5}{|l|}{ Physical activity, No. (\%) } \\
\hline Sedentary & $162(3.6)$ & $31(2.1)$ & $44(2.9)$ & $87(5.6)$ \\
\hline Low & $877(19.2)$ & $201(13.6)$ & $267(17.4)$ & $409(26.3)$ \\
\hline Medium & $2456(53.8)$ & $810(54.8)$ & $849(55.4)$ & $797(51.3)$ \\
\hline High & $1067(23.4)$ & $434(29.4)$ & $374(24.4)$ & $259(16.7)$ \\
\hline Missing & $2(0.0)$ & $1(0.1)$ & $0(0.0)$ & $1(0.1)$ \\
\hline Social detachment, No. $(\%)^{c}$ & $414(9.1)$ & $113(7.7)$ & $126(8.2)$ & $175(11.3)$ \\
\hline Missing & $395(8.7)$ & $123(8.3)$ & $128(8.3)$ & $144(9.3)$ \\
\hline External locus of control, No. (\%) & $2979(65.3)$ & $906(61.3)$ & $1000(65.2)$ & $1073(69.1)$ \\
\hline Missing & $268(5.9)$ & $78(5.3)$ & $82(5.4)$ & $108(7.0)$ \\
\hline
\end{tabular}

$\mathrm{BMI}=$ body mass index; $\mathrm{IQR}=$ interquartile range; $\mathrm{NA}=$ not applicable.

Note: Characteristics were assessed in 2002-2003, except for BMI, which was assessed in the 2004-2005 nurse visit. Covariates with no row for missing data had no missing data.

a Educational attainment was categorized into higher education/degree, intermediate (secondary education/high school), or no qualifications.

b Physical activity was assessed using methodology from the Allied Dunbar fitness survey.

"Participants were considered "socially detached" if they were detached from at least 3 out of 4 assessed domains; civic participation, leisure activities, cultural engagement, and social networks (Supplemental Appendix, available at http://www.AnnFamMed.org/content/16/4/322/suppl/DC1/).

'External locus of control means believing that life events are outside of one's control. 
in Table 2. The mean follow-up period was 10.14 years ( $\mathrm{SD}=0.26$ years). Of the 1,477 participants with no initial conditions, 377 (25.5\%) developed incident multimorbidity, and $901(61.0 \%)$ reported 1 or more incident conditions. Similarly, 1,001 of 1,534 (65.3\%) participants with a single condition in 2002-2003 reported 1 or more new conditions (and therefore incident multimorbidity) within 10 years.

Hypertension and arthritis were the most prevalent and the most commonly comorbid conditions in 2012-2013 (Figure 1). The overall prevalence of multimorbidity in $2012-2013$ was $63.5 \%$ (95\% CI, $62.1 \%$ $64.9 \%)$. Findings from the time-to-event analyses are displayed in Table 3 and Table 4.

\section{Factors Associated With Incident Multimorbidity}

The following associations were found for individuals with no baseline conditions (Table 3):

Incidence of multimorbidity accelerated with increasing age (linear trend, $P<.001$ ). There was a threshold effect for wealth, in that the least wealthy were more than twice as likely to develop incident multimorbidity at any wave as the wealthiest (hazard ratio $[H R]=2.19 ; 95 \% C I, 1.50-3.19 ; P<.001)$. Sex, education, and living alone were not significant.

Greater risk of multimorbidity at any wave was associated with being obese ( $\mathrm{HR}=1.92 ; 95 \% \mathrm{CI}, 1.43$ $2.59 ; P<.001$ ), and decreasing physical activity (linear trend, $P=.031)$. Believing life events are outside one's control (external locus of control) represented a $41 \%$ increased risk of multimorbidity at any wave (95\% $\mathrm{CI}, 10 \%-82 \% ; P=.007)$. Smoking behavior and social detachment were not associated.

\section{Factors Associated With an Incident Condition}

The model investigating factors associated with any increase in reported conditions (Table 3 ) showed trends similar to the model for individuals with no initial conditions. Increasing age, being in the least wealthy quintile, being obese, decreasing physical activity, and having an external locus of control were all significantly associated with acquiring an incident condition. Additionally, being a current smoker accelerated the acquisition of an incident condition $(\mathrm{HR}=1.21 ; 95 \% \mathrm{CI} 1.07-1.36 ; P=.002)$, with a marginal trend for having smoked in the past.

\section{Impact of Individual Conditions}

In the model comparing the effects of individual conditions on incident multimorbidity (Table 4), the conditions significantly more predictive than hypertension (the modal category used as the reference) were arrhythmia $(\mathrm{HR}=1.55 ; 95 \% \mathrm{CI}, 1.06-2.26 ; P=.024)$, chronic obstructive pulmonary disease (COPD) $(\mathrm{HR}=2.32 ; 95 \% \mathrm{CI}, 1.55-3.46 ; P<.001)$ and asthma $(\mathrm{HR}=1.33 ; 95 \% \mathrm{CI}, 1.05-1.70 ; P<.019)$.

\section{Sensitivity Analyses}

We conducted further analyses using outcome measures derived from condition counts that separated ischemic heart disease into angina and myocardial

Table 2. Prevalence of Multimorbidity and Individual Conditions From 2002-2003 to 2012-2013 in the Full Sample $(\mathrm{N}=4,564)$

\begin{tabular}{lccrrrr}
\hline Condition & 2002-2003 & 2004-2005 & 2006-2007 & 2008-2009 & 2010-2011 & 2012-2013 \\
\hline Multimorbidity, No. (\%) & $1,553(34.0)$ & $1,885(41.3)$ & $2,166(47.5)$ & $2,445(53.6)$ & $2,695(59.1)$ & $2,897(63.5)$ \\
$\quad$ Mean (SD), No. & $1.21(1.16)$ & $1.42(1.26)$ & $1.62(1.35)$ & $1.81(1.41)$ & $2.01(1.49)$ & $2.17(1.53)$ \\
Hypertension, No. (\%) & $1,564(34.3)$ & $1,844(40.4)$ & $2,067(45.3)$ & $2,230(48.9)$ & $2,377(52.1)$ & $2,472(54.2)$ \\
Ischemic heart disease, No. (\%) & $391(8.6)$ & $454(10.0)$ & $512(11.2)$ & $571(12.5)$ & $627(13.7)$ & $670(14.7)$ \\
Congestive heart failure, No. (\%) & $16(0.4)$ & $18(0.4)$ & $22(0.5)$ & $23(0.5)$ & $33(0.7)$ & $44(1.0)$ \\
Arrhythmia, No. (\%) & $250(5.5)$ & $350(7.7)$ & $420(9.2)$ & $495(10.9)$ & $581(12.7)$ & $663(14.5)$ \\
Diabetes, No. (\%) & $241(5.3)$ & $295(6.5)$ & $379(8.3)$ & $456(10.0)$ & $530(11.6)$ & $582(12.8)$ \\
Stroke, No. (\%) & $112(2.5)$ & $149(3.3)$ & $174(3.8)$ & $216(4.7)$ & $258(5.7)$ & $304(6.7)$ \\
COPD, No. (\%) & $209(4.6)$ & $257(5.6)$ & $289(6.3)$ & $328(7.2)$ & $381(8.4)$ & $427(9.4)$ \\
Asthma, No. (\%) & $534(11.7)$ & $591(13.0)$ & $621(13.6)$ & $656(14.4)$ & $689(15.1)$ & $707(15.5)$ \\
Arthritis, No. (\%) & $1,364(29.9)$ & $1,631(35.7)$ & $1,848(40.5)$ & $2,023(44.3)$ & $2,179(47.7)$ & $2,324(50.9)$ \\
Osteoporosis, No. (\%) & $196(4.3)$ & $277(6.1)$ & $346(7.6)$ & $419(9.2)$ & $509(11.2)$ & $582(12.8)$ \\
Cancer, No. (\%) & $231(5.1)$ & $305(6.7)$ & $361(7.9)$ & $415(9.1)$ & $527(11.7)$ & $604(13.2)$ \\
Parkinson's disease, No. (\%) & $5(0.1)$ & $12(0.3)$ & $20(0.4)$ & $24(0.5)$ & $31(0.7)$ & $39(0.9)$ \\
Affective MHC, No. (\%) & $362(7.9)$ & $270(5.9)$ & $304(6.7)$ & $334(7.3)$ & $364(8.0)$ & $381(8.4)$ \\
Psychotic MHC, No. (\%) & $24(0.5)$ & $26(0.6)$ & $33(0.7)$ & $37(0.8)$ & $45(1.0)$ & $53(1.2)$ \\
Dementia, No. (\%) & $12(0.3)$ & $15(0.3)$ & $19(0.4)$ & $28(0.6)$ & $41(0.9)$ & $62(1.4)$ \\
\hline CopD = chronic obstructive pulmonary disease; MHC mental health condition. & & &
\end{tabular}




\section{Figure 1. Prevalence of comorbidities on the x-axis for participants who have the condition on the} $y$-axis, with associated relative risks (data from 2012-2013).

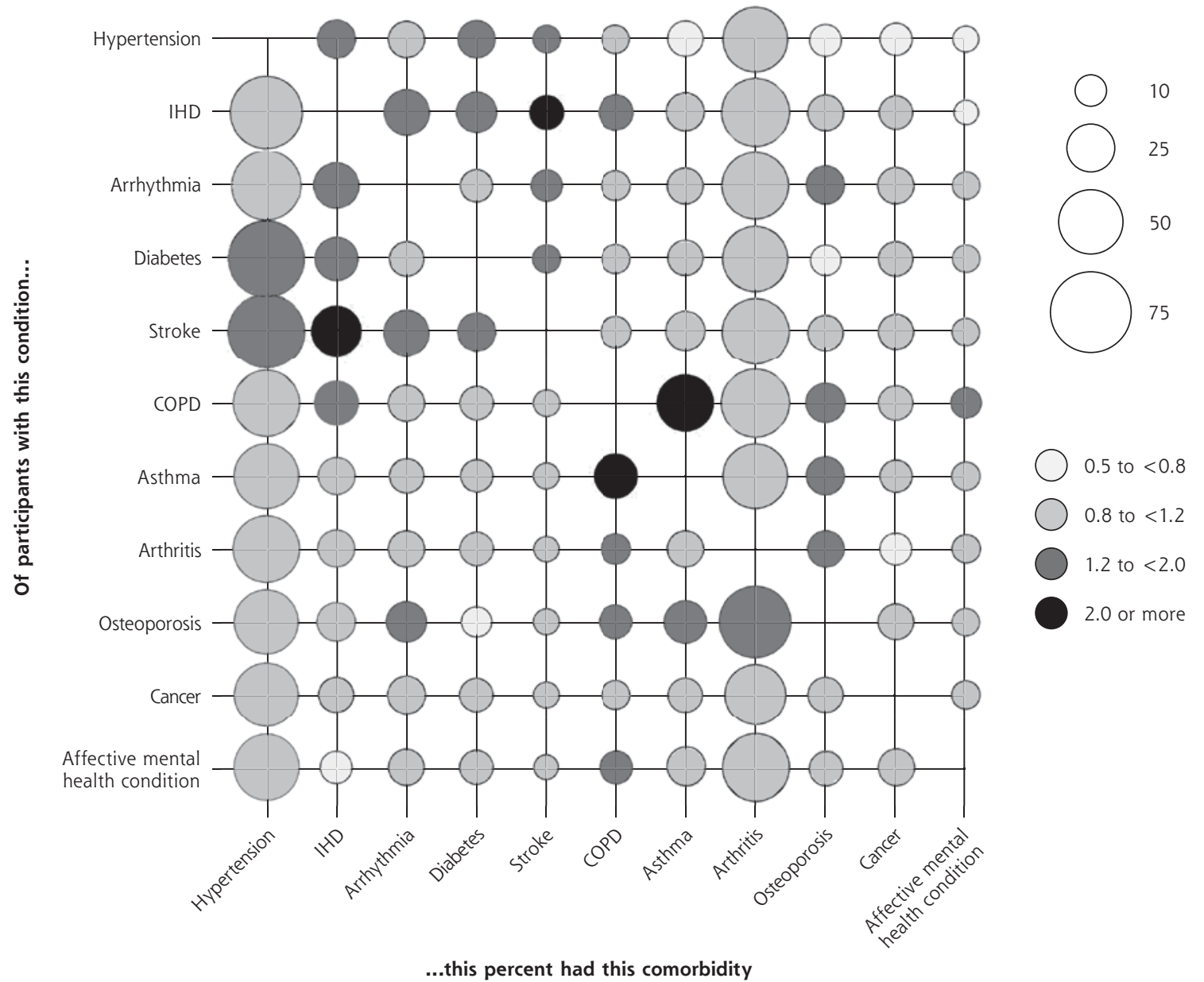

COPD = chronic obstructive pulmonary disease; IHD = ischemic heart disease

Note: Conditions with a prevalence $<5 \%$ were excluded (see Table 2 ). Relative risks are for having the comorbidity on the $x$-axis given the individual has the condition on the $y$-axis.

infarction, and combined COPD and asthma into a respiratory condition. The pattern of results described above was unaltered.

\section{DISCUSSION}

Our analysis of a large, nationally representative cohort, followed up for 10 years, identified a number of sociodemographic and lifestyle factors associated with incident multimorbidity, which were similar across baseline morbidity groups, and identified specific conditions associated with a relatively increased risk of developing multimorbidity.

\section{Comparison With Previous Studies}

Our findings confirm previous consistent findings for 2 sociodemographic factors: increased risk of multimorbid- ity with older age and lower socioeconomic status. ${ }^{4,16,2}$ The lack of association with female sex and with education is not new; previous findings are inconsistent on the association of these 2 factors with multimorbidity. ${ }^{16}$ Our observation that lower physical activity, higher BMI, smoking, and external locus of control are associated with increased risk of multimorbidity confirms previous findings. ${ }^{21,29-33}$ Our findings extend knowledge of this area in one further regard: we found that COPD, asthma, and arrhythmias are associated with higher risk of multimorbidity, thereby facilitating the identification of highrisk populations based on clinical diagnoses.

\section{Strengths and Limitations}

The longitudinal, prospective nature of these data, the consistency with previous studies, the simultaneous adjustment for multiple associated factors, and the 
observed linear trends (indicative of dose-response relationships) provide support for a causal relationship between the identified factors and incident multimorbidity. The key strengths of ELSA are the size of the cohort, and the breadth of sophisticated measures available for use as covariates, spanning socioeconomic, lifestyle, and health behavior domains. These measures

\section{Table 3. Effect of Baseline Characteristics on Time to Developing Incident Multimorbidity Between 2002-2003 and 2012-2013: Complementary Log-Log Models}

\begin{tabular}{|c|c|c|c|c|}
\hline \multirow[b]{2}{*}{ Characteristic } & \multicolumn{2}{|c|}{$\begin{array}{l}\text { No Condition in 2002- } \\
2003 \text { ( } n=1,477 \text { ) and } \\
\geq 2 \text { Incident Conditions } \\
\text { (Multimorbidity) by } \\
\text { 2012-2013 }\end{array}$} & \multicolumn{2}{|c|}{$\begin{array}{c}\text { Any Number of } \\
\text { Conditions in 2002- } \\
2003(n=4,564) \text { and } \\
\geq 1 \text { Incident Conditions } \\
\text { by } 2012-2013\end{array}$} \\
\hline & HR $(95 \% \mathrm{Cl})$ & $P$ Value & HR $(95 \% \mathrm{Cl})$ & $P$ Value \\
\hline Age, y & Linear trend & $<.001$ & Linear trend & $<.001$ \\
\hline $50-54$ & 1.00 [Reference] & $\ldots$ & 1.00 [Reference] & 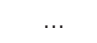 \\
\hline $55-59$ & $1.44(1.05-1.99)^{\mathrm{a}}$ & $.025^{\mathrm{a}}$ & $1.29(1.14-1.45)^{\mathrm{a}}$ & $<.001^{\mathrm{a}}$ \\
\hline $60-64$ & $1.85(1.31-2.61)^{\mathrm{a}}$ & $<.001^{\mathrm{a}}$ & $1.42(1.25-1.62)^{\mathrm{a}}$ & $<.001^{\mathrm{a}}$ \\
\hline $65-69$ & $2.93(2.08-4.13)^{a}$ & $<.001^{\mathrm{a}}$ & $1.49(1.31-1.70)^{\mathrm{a}}$ & $<.001^{\mathrm{a}}$ \\
\hline$\geq 70$ & $2.58(1.83-3.64)^{a}$ & $<.001^{\mathrm{a}}$ & $1.49(1.31-1.70)^{a}$ & $<.001^{\mathrm{a}}$ \\
\hline Female (vs male) & $1.14(0.86-1.50)$ & .360 & $1.10(0.99-1.21)$ & .072 \\
\hline Wealth quintiles & Linear trend & $.001^{\mathrm{a}}$ & Linear trend & $.002^{\mathrm{a}}$ \\
\hline 1 Wealthiest & 1.00 [Reference] & $\ldots$ & 1.00 [Reference] & $\ldots$ \\
\hline 2 & $1.27(0.89-1.80)$ & .185 & $0.97(0.85-1.10)$ & .620 \\
\hline 3 & $1.41(1.00-1.97)$ & .049 & $1.08(0.95-1.23)$ & .215 \\
\hline 4 & $1.23(0.85-1.78)$ & .269 & $1.11(0.97-1.26)$ & .120 \\
\hline 5 Least wealthy & $2.19(1.50-3.19)^{a}$ & $<.001^{\mathrm{a}}$ & $1.22(1.06-1.39)^{\mathrm{a}}$ & $.005^{\mathrm{a}}$ \\
\hline Educational attainment & Linear trend & .058 & Linear trend & .923 \\
\hline Degree / higher ed & 1.00 [Reference] & $\ldots$ & 1.00 [Reference] & $\ldots$ \\
\hline Intermediate & $0.95(0.73-1.23)$ & .701 & $1.04(0.94-1.15)$ & .413 \\
\hline No qualification & $0.73(0.53-1.00)$ & .051 & $1.00(0.89-1.12)$ & .993 \\
\hline Lives alone (vs cohabits) & $0.93(0.71-1.21)$ & .580 & $1.08(0.98-1.19)$ & .128 \\
\hline BMI category (2004) & Linear trend & $<.001^{\mathrm{a}}$ & Linear trend & $<.001^{\mathrm{a}}$ \\
\hline $\begin{array}{l}\text { Underweight or normal } \\
\text { weight }\end{array}$ & 1.00 [Reference] & $\ldots$ & 1.00 [Reference] & $\cdots$ \\
\hline Overweight & $1.15(0.87-1.52)$ & .339 & $1.10(0.99-1.21)$ & .070 \\
\hline Obese & $1.92(1.43-2.59)^{\mathrm{a}}$ & $<.001^{\mathrm{a}}$ & $1.27(1.14-1.42)^{\mathrm{a}}$ & $<.001^{\mathrm{a}}$ \\
\hline \multicolumn{5}{|l|}{ Smoking behavior } \\
\hline Never smoked & 1.00 [Reference] & $\ldots$ & 1.00 [Reference] & $\ldots$ \\
\hline Smoked in past & $1.12(0.88-1.43)$ & .359 & $1.09(1.00-1.19)$ & .050 \\
\hline Current smoker & $1.22(0.87-1.70)$ & .248 & $1.21(1.07-1.36)^{\mathrm{a}}$ & $.002^{\mathrm{a}}$ \\
\hline Physical activity & Linear trend & $.031^{\mathrm{a}}$ & Linear trend & $.004^{\mathrm{a}}$ \\
\hline High & 1.00 [Reference] & $\ldots$ & 1.00 [Reference] & $\ldots$ \\
\hline Medium & $1.3(1.00-1.70)$ & .051 & $1.08(0.97-1.19)$ & .149 \\
\hline Low & $1.43(1.02-2.00)^{\mathrm{a}}$ & $.039^{a}$ & $1.19(1.06-1.35)^{\mathrm{a}}$ & $.004^{\mathrm{a}}$ \\
\hline Social detachment (vs none) & $1.16(0.77-1.72)$ & .480 & $1.07(0.93-1.22)$ & .360 \\
\hline $\begin{array}{l}\text { External locus of control } \\
\text { (vs internal) }\end{array}$ & $1.41(1.10-1.82)^{\mathrm{a}}$ & $.007^{\mathrm{a}}$ & $1.13(1.03-1.23)^{\mathrm{a}}$ & $.010^{\mathrm{a}}$ \\
\hline \multicolumn{5}{|c|}{$\mathrm{BMI}=$ body mass index $; \mathrm{HR}=$ hazard ratio. } \\
\hline \multicolumn{5}{|c|}{$\begin{array}{l}\text { Note: Complementary log-log models are the discrete time equivalent of Cox proportional hazards models } \\
\text { for continuous time. The reference category for each covariate is the first category listed. A HR }>1.00 \text { indi- } \\
\text { cates increased risk, whereas an HR of }<1.00 \text { indicates reduced risk. Models were corrected for differential } \\
\text { nonresponse using longitudinal sample weighting. }\end{array}$} \\
\hline a Significant association. & & & & \\
\hline
\end{tabular}

allowed a more thorough and comprehensive investigation of risk factors than is usually achievable with electronic health record data sets.

The presence of conditions was self-reported by participants, which may be less reliable than ascertaining diagnoses from medical records. The reports of conditions were also restricted to those included in the ELSA interview. As such, the prevalence and incidence rates reported are likely to be underestimated. Self-reports of conditions may also depend on the number of physician visits, for which we were not able to control. Although the initial ELSA cohort was sampled to be representative of private residents in England aged 50 years and older, loss to follow-up during successive waves meant that representativeness was lost. Sample weights to adjust for differential nonresponse were provided with the ELSA data, which were used in all relevant analyses. Our measure for locus of control was a single, unvalidated item, and it could not distinguish between a genuine external locus or a functionally external locus because of a lack of resources or abilities.

\section{Implications for Policy, Clinical Practice, and Research}

Whereas much of current efforts are being aimed at improving care processes and outcomes for people with multimorbidity, ${ }_{1}^{10,34}$ our findings suggest that there is scope for a prevention strategy focusing on reducing the incidence of multimorbidity. A number of the factors in our analyses are risk factors for multiple individual conditions (smoking behavior, being obese, and low levels of physical activity) and are amenable to change through available behavior-change interventions. Locus of control has been linked to behavior change, ${ }^{31,35}$ and can be successfully modified by existing interventions. ${ }^{36}$

Taken together, these findings suggest that future work aimed at reducing the incidence of multimorbidity should design and 


\section{Table 4. Relative Association Between the Presence of Individual Conditions on Time to Developing Incident Multimorbidity Between 2002-2003 and 2012-2013: Complementary Log-Log Model}

\begin{tabular}{|c|c|c|}
\hline Condition & HR $(95 \% \mathrm{CI})$ & $P$ Value \\
\hline Hypertension & 1.00 [Reference] & $\ldots$ \\
\hline Ischemic heart disease & $1.27(0.91-1.78)$ & .162 \\
\hline Arrhythmia & $1.55(1.06-2.26)^{\mathrm{a}}$ & $.024^{\mathrm{a}}$ \\
\hline Diabetes mellitus & $1.06(0.63-1.78)$ & .839 \\
\hline COPD & $2.32(1.55-3.46)^{\mathrm{a}}$ & $<.001^{\mathrm{a}}$ \\
\hline Asthma & $1.33(1.05-1.70)^{\mathrm{a}}$ & $<.019^{a}$ \\
\hline Arthritis (any) & $0.98(0.83-1.16)$ & .819 \\
\hline Osteoporosis & $1.32(0.87-2.01)$ & .185 \\
\hline Cancer (any) & $1.19(0.86-1.63)$ & .295 \\
\hline $\begin{array}{l}\text { Affective mental health condition } \\
\text { (any) }\end{array}$ & $0.97(0.71-1.31)$ & .831 \\
\hline Other $^{b}$ & $1.21(0.64-2.30)$ & .552 \\
\hline \multicolumn{3}{|c|}{ COPD = chronic obstructive pulmonary disease; HR = hazard ratio. } \\
\hline \multicolumn{3}{|c|}{$\begin{array}{l}\text { Note: From a sample of participants having } 1 \text { condition in 2002-2003 } \\
\text { ( } n=1,534) \text {, and an outcome of } 1 \text { or more incident conditions. Complementary } \\
\text { log-log models are discrete time equivalent of Cox proportional hazards mod- } \\
\text { els for continuous time. This model adjusted for all baseline patient character- } \\
\text { istics, and differential nonresponse using longitudinal sample weighting. HR } \\
>1.00 \text { represents increased risk; an HR of }<1.00 \text { indicates reduced risk. }\end{array}$} \\
\hline \multicolumn{3}{|c|}{$\begin{array}{l}\text { a Conditions significantly more more likely than hypertension to be associated } \\
\text { with incident multimorbidity. } \\
\text { b Includes participants with conditions with low prevalence; congestive heart } \\
\text { failure, stroke, psychotic mental health condition, and dementia/Alzheimer's } \\
\text { (Table 2). Combined, these individuals in the "other" category accounted for } \\
<1 \% \text { of the sample. }\end{array}$} \\
\hline
\end{tabular}

evaluate interventions that include evidence-based components addressing behavioral change for promoting healthy lifestyles. Additionally, such interventions should seek to help patients gain a more internal health-related locus of control to empower them to achieve and maintain such change, with the potential for synergistic effects. The cost-effectiveness of such interventions should be compared against current practices in the delivery of condition-specific preventative care. In the absence of such more complex interventions, health policy and clinical practice oriented to the implementation and delivery of existing behavior change should be prioritized. High-risk populations can be defined based on the sociodemographic and clinical factors identified in this study.

Identifying specific patterns in the development of multimorbidity was beyond the scope of this study. Further research on multimorbidity clusters is needed to clarify relevant mechanisms: co-prevalence with increasing age (eg, osteoporosis and arthritis) vs shared pathophysiology (eg, hypertension and coronary artery disease). Future work should also account for morbidity burden - for example, the level of control of such conditions as diabetes, ischemic heart disease, and arthritis-which may provide a more meaningful mea- sure of morbidity to clinicians and patients than using counts of conditions.

To read or post commentaries in response to this article, see it online at http://www.AnnFamMed.org/content/16/4/322.

Key words: multimorbidity; epidemiology; incidence; determinants; patient characteristics; older people

Submitted November 20, 2017; submitted, revised, April 3, 2018; accepted April 19, 2018.

Funding support: There was no direct funding for this study. Dr Mounce was supported by the National Health Service, Cambridgeshire, and through an National Institute for Health Research Clinical Scientist Award granted to Dr Valderas.

Supplementary materials: Available at http://www.AnnFamMed. org/content/16/4/322/suppl/DC1/.

\section{References}

1. Valderas JM, Starfield B, Sibbald B, Salisbury C, Roland M. Defining comorbidity: implications for understanding health and health services. Ann Fam Med. 2009;7(4):357-363.

2. World Health Organization. Global status report on noncommunicable diseases 2010: description of the global burden of NCDs, ther risk factors and determinants. http://www.who.int/nmh/publications/ ncd_report2010/en/. Published Apr 2011. Accessed Oct 21, 2014.

3. Uijen AA, van de Lisdonk EH. Multimorbidity in primary care: prevalence and trend over the last 20 years. Eur J Gen Pract. 2008; 14(Suppl 1):28-32.

4. Barnett K, Mercer SW, Norbury M, Watt G, Wyke S, Guthrie B. Epidemiology of multimorbidity and implications for health care, research, and medical education: a cross-sectional study. Lancet. 2012;380(9836):37-43.

5. Fortin M, Lapointe L, Hudon C, Vanasse A, Ntetu AL, Maltais D. Multimorbidity and quality of life in primary care: a systematic review. Health Qual Life Outcomes. 2004;2:51.

6. Mujica-Mota RE, Roberts M, Abel G, et al. Common patterns of morbidity and multi-morbidity and their impact on health-related quality of life: evidence from a national survey. Qual Life Res. 2015; 24(4):909-918.

7. Gijsen R, Hoeymans N, Schellevis FG, Ruwaard D, Satariano WA, van den Bos GA. Causes and consequences of comorbidity: a review. J Clin Epidemiol. 2001;54(7):661-674.

8. Salisbury C, Johnson L, Purdy S, Valderas JM, Montgomery AA. Epidemiology and impact of multimorbidity in primary care: a retrospective cohort study. Br J Gen Pract. 2011;61(582):e12-21.

9. Payne RA, Abel GA, Guthrie B, Mercer SW. The effect of physical multimorbidity, mental health conditions and socioeconomic deprivation on unplanned admissions to hospital: a retrospective cohort study. CMAJ. 2013;185(5):E221-8.

10. Smith SM, Wallace E, O'Dowd T, Fortin M. Interventions for improving outcomes in patients with multimorbidity in primary care and community settings. Cochrane Database Syst Rev. 2016;3:CD006560.

11. Guthrie B, Payne K, Alderson P, McMurdo ME, Mercer SW. Adapting clinical guidelines to take account of multimorbidity. BMJ. 2012; 345:e6341.

12. Boyd C, Fortin M. Future of multimorbidity research: how should understanding of multimorbidity inform health system design? Public Health Rev. 2010;32(2):451-474.

13. Fortin M, Bravo G, Hudon C, Vanasse A, Lapointe L. Prevalence of multimorbidity among adults seen in family practice. Ann Fam Med. 2005;3(3):223-228. 
14. Parekh AK, Goodman RA, Gordon C, Koh HK. Managing multiple chronic conditions: a strategic framework for improving health outcomes and quality of life. Public Health Rep. 2011;126(4):460-71.

15. Fortin M, Soubhi $H$, Hudon C, Bayliss EA, van den Akker M. Multimorbidity's many challenges. BMJ. 2007;334(7602):1016-1017.

16. Violán C, Foguet-Boreu Q, Flores-Mateo G, Salisbury C, Blom J, Freitag $M$, et al. Prevalence, determinants and patterns of multimorbidity in primary care: a systematic review of observational studies. PloS One. 2014;9(7):e102149.

17. Glynn LG, Valderas JM, Healy $P$, et al. The prevalence of multimorbidity in primary care and its effect on health care utilization and cost. Fam Pract. 2011;28(5):516-523.

18. Marengoni A, Winblad B, Karp A, Fratiglioni L. Prevalence of chronic diseases and multimorbidity among the elderly population in Sweden. Am J Public Health. 2008;98(7):1198-1200.

19. Violán C, Foguet-Boreu Q, Hermosilla-Pérez E, Valderas JM, Bolíbar $B$, Fàbregas-Escurriola $M$, et al. Comparison of the information provided by electronic health records data and a population health survey to estimate prevalence of selected health conditions and multimorbidity. BMC Public Health. 2013;13:251.

20. France EF, Wyke S, Gunn JM, Mair FS, McLean G, Mercer SW. Multimorbidity in primary care: a systematic review of prospective cohort studies. Br J Gen Pract. 2012;62(597):e297-307.

21. Katikireddi SV, Skivington K, Leyland AH, Hunt K, Mercer SW. The contribution of risk factors to socioeconomic inequalities in multimorbidity across the lifecourse: a longitudinal analysis of the Twenty-07 cohort. BMC Med. 2017;15(1):152.

22. Le Reste JY, Nabbe $P$, Lingner $H$, et al. What research agenda could be generated from the European General Practice Research Network concept of Multimorbidity in Family Practice? BMC Fam Pract. 2015;16(1):125.

23. Taylor R, Conway L, Calderwood L, et al. Health, Wealth and Lifestyles of the Older Population in England: The 2002 English Longitudinal Study of Ageing: Technical Report. London, England: Institute of Fiscal Studies; 2007.

24. Cheshire H, Hussey D, Medina J, et al. Financial Circumstances, Health and Well-Being of the Older Population in England: The 2008 English Longitudinal Study of Ageing: Technical Report. London, England: Institute of Fiscal Studies; 2012.

25. Scholes S, Medina J, Cheshire H, Cox K, Hacker E, Lessof C. Living in the 21st Century: Older People in England: The 2006 English Longitudinal Study of Ageing: Technical Report. London, England: Institute of Fiscal Studies; 2009.
26. Scholes S, Taylor R, Cheshire H, Cox K, Lessof C. Retirement, Health and Relationships of the Older Population in England: The 2004 English Longitudinal Study of Ageing: Technical Report. London, England: Institute of Fiscal Studies; 2008.

27. Sports Council, Allied Dunbar Assurance PLC, Health Education Authority. Allied Dunbar National Fitness Survey: Main Findings. London, England: Allied Dunbar, the Health Education Authority and Sports Council; 1992.

28. Banks J, Nazroo J, Steptoe A. The Dynamics of Ageing: Evidence from the English Longitudinal Study of Ageing 2002-10 (Wave 5). London, England: Institute of Fiscal Studies; 2012.

29. Dhalwani NN, O'Donovan G, Zaccardi F, et al. Long terms trends of multimorbidity and association with physical activity in older English population. Int J Behav Nutr Phys Act. 2016;13:8.

30. Dhalwani NN, Zaccardi F, O'Donovan G, et al. Association Between Lifestyle Factors and the Incidence of Multimorbidity in an Older English Population. J Gerontol A Biol Sci Med Sci. 2017;72(4):528-534.

31. Berglund E, Lytsy P, Westerling R. The influence of locus of control on self-rated health in context of chronic disease: a structural equation modeling approach in a cross sectional study. BMC Public Health. 2014;14:492.

32. van den Akker M, Buntinx F, Metsemakers JF, van der Aa M, Knottnerus JA. Psychosocial patient characteristics and GP-registered chronic morbidity: a prospective study. J Psychosom Res. 2001; 50(2):95-102.

33. van den Akker M, Vos R, Knottnerus JA. In an exploratory prospective study on multimorbidity general and disease-related susceptibility could be distinguished. J Clin Epidemiol. 2006;59(9):934-939.

34. Ricci-Cabello I. Violán C, Foguet-Boreu Q, Mounce LTA, Valderas JM. Impact of multi-morbidity on quality of healthcare and its implications for health policy, research and clinical practice. A scoping review. Eur J Gen Pract. 2015;21(3):192-202

35. Mautner D, Peterson B, Cunningham A, Ku B, Scott K, LaNoue M. How multidimensional health locus of control predicts utilization of emergency and inpatient hospital services. J Health Psychol. 2017; 22(3):314-323.

36. Wolinsky FD, Vander Weg MW, Martin R, et al. Does cognitive training improve internal locus of control among older adults? J Gerontol B Psychol Sci Soc Sci. 2010;65(5):591-598. 